\title{
GROWTH, FATTY ACID PROFILE IN MAJOR LIPID CLASSES AND LIPID FLUIDITY OF AURANTIOCHYTRIUM MANGROVEI SK-02 AS A FUNCTION OF GROWTH TEMPERATURE
}

\author{
Kanokwan Chodchoey*; Cornelis Verduyn
}

Department of Biotechnology, Faculty of Science, Mahidol University, Bangkok, Thailand.

Submitted: February 01, 2011; Returned to authors for corrections: March 29, 2011; Approved: August 15, 2011.

\begin{abstract}
Aurantiochytrium mangrovei Sk-02 was grown in a medium containing glucose (40 g/l), yeast extract (10 $\mathrm{g} / \mathrm{L})$ and sea salts $(15 \mathrm{~g} / \mathrm{L})$ at temperatures ranging from 12 to $35^{\circ} \mathrm{C}$. The fastest growth $\left(\mu_{\max }=0.15 \mathrm{~h}^{-1}\right)$ and highest fatty acid content of $415 \mathrm{mg} / \mathrm{g}$-dry cell weight were found in the cells grown at $30^{\circ} \mathrm{C}$. However, the cells grown at $12^{\circ} \mathrm{C}$ showed the highest percentage of polyunsaturated fatty acid (PUFA) (48.6\% of total fatty acid). The percentage of docosahexaenoic acid (DHA) and pentadecanoic acid (C15:0) decreased with an increase in the growth temperature, whereas, palmitic acid (C16:0), stearic acid (C18:0) and DPA (C22:5n6) increased with an increase in the growth temperature. The composition of the major lipid class $(\% \mathrm{w} / \mathrm{w})$ was slightly affected by the growth temperature. The fluidity of the organelle membrane or intracellular lipid (by DPH measurement) decreased with an increase in the growth temperatures, while the plasma membrane fluidity (by TMA-DPH measurement) could still maintain its fluidity in a wide range of temperatures $\left(15-37^{\circ} \mathrm{C}\right)$. Furthermore, the distribution of DHA was found to be higher $(36-54 \%)$ in phospholipid (PL) as compared to neutral lipid (NL) (20 - 41\%).
\end{abstract}

Key words: Anisotropy measurement; Aurantiochytrium sp.; Docosahexaenoic acid; lipid class composition; membrane fluidity.

\section{INTRODUCTION}

Docosahexaenoic acid (C22:6n3; DHA) is an omega-3 polyunsaturated fatty acid (PUFA) and one of the essential fatty acids necessary for infants during brain and retinal development. In mammals, DHA can be either acquired directly from the diet or there is a limited ability to synthesize it from linoleic acid $(\mathrm{C} 18: 3 \mathrm{n} 3)$ or eicosahexaenoic acid (C20:5n3) obtained from the diet as precursors, with DHA finally obtained via a retro-conversion of $\mathrm{C} 24: 6 \mathrm{n} 3$ to $\mathrm{C} 22: 6 \mathrm{n} 3$ by the Sprecher pathway $(17,19)$. The benefits of DHA (C22:6n3) have been extensively studied in aspects of nutritional and clinical effects in humans, animals and aquaculture. It is found as a major constituent of the phospholipid membrane in the brain and in the rod outer segment in the retina (up to $60 \%$ DHA) (9). DHA has been shown to improve cognitive performance in healthy adults and also play an important role in a circulatory system as DHA can 
increase flexibility and strength of arterial walls (3). The main source of DHA is from fish and seafood. In addition, many researches have been found that a number of microalgae in the group of thraustochytrids produce a significant amount of DHA. Cryptheconidium cohnii and the thraustochytrid, Schizochytrium sp., are now commercially applied to DHA production (21). Although, the production of fish oil does not involve high technologies in the cultivation and oil extraction like the production of DHA oil from microalgae. However, the population of fish is reduced and fish could get contaminated with mercury. Furthermore, the production of fish oil might affect the balance of marine ecosystems. Thus, DHAcontaining oil from marine microalgae could be a sustainable source of omega-3 oil. In addition, many studies have shown that DHA-containing oil from marine microalgae is effective and probably safer than fish oil in order to meet the demand for human consumption (3).

Aurantiochytrium (formerly Schizochytrium) mangrovei Sk-02, a thraustochytrid, was isolated from a mangrove forest in Hong Kong. Previous reports on growth and fatty acid production of this strain showed that high DHA production (up to $4.7 \mathrm{~g} / \mathrm{L}$ or $22.5 \%$ of dry cell weight) could be obtained from a glucose-yeast extract-sea salt medium in shake flask cultivation (24). Other studies with A. limacinum OUC88 showed the effect of temperature and salinity on the biomass and total fatty acid production (27). In a more recent study, the effect of temperature on growth and total fatty acid composition in Aurantiochytrium sp. strain mh0186 was reported (23). However, there are no reports on the fatty acid profile of the major lipid changes or the membrane fluidity in Thraustochytrids as a function of temperature. Therefore, the objectives of this research were to investigate the effect of cultivation temperature on growth, cellular fatty acid composition, fatty acid composition in major lipid classes and lipid fluidity. The results from this research might be useful for further optimization of DHA production by this strain in both triacylglycerol and phospholipid form. Moreover, the results could add more physiological information in terms of the lipid characterization and lipid fluidity of A. mangrovei Sk02 as a function of growth temperature.

\section{MATERIALS AND METHODS}

\section{Microorganism and culture conditions}

Aurantiochytrium mangrovei Sk-02 (formerly

Schizochytrium mangrovei Sk-02) was provided by Prof. Lilian L.P. Vrijmoed and Prof. Gareth Jones (City University of Hong Kong). The pure culture was maintained on a glucose-yeast extract-peptone (GYP) agar slant medium containing $10 \mathrm{~g} / \mathrm{L}$ glucose, $1 \mathrm{~g} / \mathrm{L}$ yeast extract, $1 \mathrm{~g} / \mathrm{L}$ peptone and $15 \mathrm{~g} / \mathrm{L}$ each of agar and artificial sea salts (50\% artificial seawater) and subcultured every month (24). For obtaining 18S rRNA gene sequence from this strain, a single colony from a GYP agar plate was transferred to $50 \mathrm{ml}$ tube containing $10 \mathrm{ml}$ of liquid medium consisting of $1 \mathrm{~g} / \mathrm{L}$ peptone, $2 \mathrm{~g} / \mathrm{L}$ yeast extract, $4 \mathrm{~g} / \mathrm{L}$ glucose and $15 \mathrm{~g} / \mathrm{L}$ sea salts. The culture was cultivated at $26^{\circ} \mathrm{C}$ with $150 \mathrm{rpm}$ for 1 week. Then the cells were harvested and lyophilized. After that the genomic DNA of the cells was extracted by using DNeasy Plant Mini Kit (Qiagen, Germantown, MD, USA). Polymerase chain reaction was done to amplify $18 \mathrm{~S}$ rRNA gene in the genomic DNA by using two primers: $16 \mathrm{~S} 1 \mathrm{~N}$ (forward, 5'-TCCTGCCAGTAGTCATATGC$3^{\prime}$ ) and $16 \mathrm{~S} 2 \mathrm{~N}$ (reverse, 5'-TGATCCTCT/CGCAGGTTCAC-

$\left.3^{\prime}\right)$ (23). The polymerase chain reaction (PCR) mixture composed of $50 \mu 11 \times$ Taq PCR buffer (New England Biolabs, $\mathrm{UK}), 0.2 \mathrm{mM}$ dNTP, $0.2 \mu \mathrm{M}$ of each primer (16S1N and 16S2N), $2.3 \mathrm{U}$ Taq polymerase (New England Biolabs, UK) and sterile distilled water. The PCR program started from 1 cycle of DNA denaturing at $94^{\circ} \mathrm{C}$ for $5 \mathrm{~min}$. Then the PCR was run for 40 cycles of $30 \mathrm{~s}$ at $94^{\circ} \mathrm{C}, 30 \mathrm{~s}$ at $54^{\circ} \mathrm{C}, 2 \mathrm{~min}$ at $72^{\circ} \mathrm{C}$ and followed by 1 cycle of final extension at $72^{\circ} \mathrm{C}$. The results of the $18 \mathrm{~S}$ rRNA gene sequence were aligned and compared to other microorganisms in GenBank database of the National Center for Biotechnology Information (NCBI) by using 
BLAST (Basic local alignment search). The neighbor-joining (NJ) tree was constructed by MEGA4 (22) software and CLUSTAL W. The bootstrap values were obtained from 1,000 replications of $\mathrm{NJ}$ analyses.

An inoculum was prepared by transferring $1 \mathrm{ml}$ of zoospore suspension in the well from a GYP plate to $250 \mathrm{ml}$ Erlenmeyer flask containing $50 \mathrm{ml}$ of GYP medium. The inoculum was incubated at $25^{\circ} \mathrm{C}$ in an orbital shaker at 200 rpm for $18-20 \mathrm{~h}$. Basal medium consisted of $40 \mathrm{~g} / \mathrm{L}$ glucose, $10 \mathrm{~g} / \mathrm{L}$ yeast extract (Difco, USA), $0.001 \mathrm{~g} / \mathrm{L} \mathrm{MnCl}_{2}$ with 15 $\mathrm{g} / \mathrm{L}$ artificial sea salts (SS) (Sigma, USA) with an initial $\mathrm{pH}$ of 6.5. The cultivation was performed in $500 \mathrm{~mL}$ baffled flasks containing $100 \mathrm{ml}$ culture medium. All flasks were inoculated with $5 \mathrm{~mL}$ inoculum and incubated in an orbital shaker at 200 rpm at either $12^{\circ} \mathrm{C}, 15^{\circ} \mathrm{C}, 20^{\circ} \mathrm{C}, 25^{\circ} \mathrm{C}, 30^{\circ} \mathrm{C}$ or $35^{\circ} \mathrm{C}$. Duplicate cultivation flasks were sampled and the $\mathrm{pH}$ was measured and adjusted to 6.5 by $1 \mathrm{M} \mathrm{KOH}$ or $1 \mathrm{M} \mathrm{HCl}$ during the cultivation. Virtually no growth was observed at $10^{\circ} \mathrm{C}$, whereas growth at $38^{\circ} \mathrm{C}$ resulted in a large reduction (ca. 50\%) in the biomass yield, hence these conditions were not included. During cultivation, one ml samples were taken for assay of the optical density (at $660 \mathrm{~nm}$, indicated as $\mathrm{OD}_{660}$ ) or $4 \mathrm{~mL}$ for biomass dry weight after washing with distilled water (24). When glucose in the culture medium had decreased to approximately 2 to $4 \mathrm{~g} / \mathrm{L}, 40 \mathrm{ml}$ of culture was taken for assay of cell count and cell size by haemacytometer, maximal biomass, overall fatty acid profile as well as composition of major lipid classes.

\section{Optical density measurement, biomass determination and residual glucose assay}

The culture broth $(1 \mathrm{~mL})$ was collected in $2 \mathrm{~mL}$ Eppendorf tubes and centrifuged at $10,000 \times \mathrm{g}$ for $10 \mathrm{~min}$. The pellet was washed twice with distilled water. The optical density was measured by spectrophotometer (Novaspec II, Pharmacia Biotech, Sweden) at $660 \mathrm{~nm}$. For biomass determination, cell pellets were collected by centrifugation and washed with distilled water. The weight of dried biomass was determined after freeze-drying and expressed as mg/L. The supernatants, after collecting cell pellets by centrifugation, were used for glucose measurement by a glucose oxidase kit (Glucose liquicolor, Human, Germany).

\section{Fluorescence anisotropy measurement}

Diphenyl-heaxatriene (DPH, Sigma) and trimethylammonium-diphenyl-hexatriene (TMA-DPH, Sigma) were used as probes to measure whole-cell fluorescence anisotropy of A. mangrovei Sk-02. Briefly, fresh cells were collected from cells cultivated at $15^{\circ} \mathrm{C}$ and $30^{\circ} \mathrm{C}$ with $15 \mathrm{~g} / \mathrm{L}$ SS at the early fatty acid formation phase. Cells were washed twice with distilled water. After centrifugation at $10,000 \times \mathrm{g}$ for $10 \mathrm{~min}$, cells were resuspended in $10 \mathrm{mM}$ phosphate buffered saline (PBS) to have a final $\mathrm{OD}_{660}$ of approximately 0.1 (ca.1 mg wet weight / mL). The stock solutions of DPH and TMADPH were dissolved in tetrahydrofuran (THF) and dimethyl sulfoxide (DMSO), respectively (6). A final concentration of 2 $\mu \mathrm{M}$ and $5 \mu \mathrm{M}$ of DPH and TMA-DPH, respectively were added to $1 \mathrm{~mL}$ cell suspension (final concentrations of THF and DMSO were less than 0.1\%). The same volumes of THF and DMSO without probe were added to a cell suspension as a blank control. After a fluorescence probe was added, the cells were incubated at $15^{\circ} \mathrm{C}, 30^{\circ} \mathrm{C}$ and $37^{\circ} \mathrm{C}$ for $20 \mathrm{~min}$. Steady state fluorescence anisotropy was measured with a PerkinElmer LS 55 luminescence spectrofluorometer connected to a MP-50 Open Bath Circulator (JULABO). For DPH and TMADPA, the excitation and emission wavelengths were $360 \mathrm{~nm}$ and $450 \mathrm{~nm}$, respectively. The anisotropy (r) was calculated according to the equation:

$$
\mathrm{r}=\left(\mathrm{I}_{\mathrm{vv}}-\mathrm{GF} \times \mathrm{I}_{\mathrm{vh}}\right) /\left(\mathrm{I}_{\mathrm{vv}}+2 \mathrm{GF} \times \mathrm{I}_{\mathrm{vh}}\right)
$$

where: $\mathrm{GF}=\mathrm{I}_{\mathrm{hv}} / \mathrm{I}_{\mathrm{hh}}$ is the grating factor that is an instrumental correction factor; I is the intensity of fluorescence emitted; while $\mathrm{v}$ or $\mathrm{h}$ refer to the vertical and horizontal direction, respectively. A higher value of anisotropy $(r)$ indicates a 
lower fluidity.

\section{Lipid classes separation and fatty acid analysis}

Lipids from dried cells were extracted by chloroformmethanol-distilled water (1:2:0.8 v/v/v) described by (2). The solvents were added to the dried cells in a sequence starting from chloroform, methanol and distilled water as described by (15). A mixture of dried cells and solvents was sonicated in a sonication bath for $15 \mathrm{~min}$, and then the mixtures were incubated at room temperature for $18 \mathrm{~h}$. Finally, lipids were separated by adding $1.25 \mathrm{~mL}$ chloroform and $1.25 \mathrm{~mL}$ of $1 \mathrm{M}$ $\mathrm{NaCl}$ in a mixture. After centrifugation at $1000 \times \mathrm{g}$, lipids in the chloroform phase were taken out and dried with nitrogen gas in a new vial. Twenty milligram of lipids were separated into neutral lipid (NL), free fatty acid (FFA), non-acidic phospholipid (non-aPL) and acidic phospholipid (aPL) by aminopropyl-bonded phase via a column chromatography method described by (12). Neutral lipid was first eluted from the column by adding $16 \mathrm{ml}$ of chloroform-isopropanol (2:1 $\mathrm{v} / \mathrm{v}$ ) and $8 \mathrm{~mL}$ of $1 \% \mathrm{v} / \mathrm{v}$ acetic acid in diethyl ether was then used to separate free fatty acid. Then $16 \mathrm{~mL}$ of methanol was added to the column to elute non-acidic phospholipids (nonaPL) (phosphatidyl choline; PC and phosphatidyl ethanolamine; PE). The last fraction was acidic phospholipids (aPL) (phosphatidyl inositol; PI and phosphatidyl serine; PS), which was eluted by $8 \mathrm{ml}$ of chloroform-methanol-3N $\mathrm{HCl}$ $(100: 200: 1 \mathrm{v} / \mathrm{v} / \mathrm{v})$. The solvent was evaporated in a vacuum incubator (Gallenkamp, Germany). Dried lipid samples from every fraction were weighed and resuspended in chloroformmethanol $(2: 1 \mathrm{v} / \mathrm{v})$. The purity of each lipid class was checked by thin layer chromatography (TLC) using silica gel 60 plates. The solvent used for TLC was hexane-diethyl ether-acetic acid $(70: 30: 1 \mathrm{v} / \mathrm{v} / \mathrm{v})$. The plate was stained with $3 \% \mathrm{w} / \mathrm{v}$ copper sulfate in $30 \% \mathrm{v} / \mathrm{v}$ sulfuric acid and heated at $120^{\circ} \mathrm{C}$ for 15 $\min$.

Lipids extracted from dried cells as well as lipid from individual lipid classes were methyl esterified in $4 \% \mathrm{v} / \mathrm{v}$ conc. sulfuric acid in methanol with $0.1 \%$ of 2,6-Di-tert-butyl-4methylphenol (BHT) (24). The internal standard was C19:0. Fatty acid methyl esters (FAMEs) were injected on a Shimadzu GC-17A gas chromatography equipped with an Omegawax $250^{\mathrm{TM}}(30 \mathrm{~m} \times 0.25 \mathrm{~mm})$ column (Supelco, USA), an autoinjector and flame ionization detector. Injector and detector temperatures were $250^{\circ} \mathrm{C}$ and $260^{\circ} \mathrm{C}$ respectively, with helium as carrier gas at a linear velocity of $30 \mathrm{~cm} / \mathrm{s}$. Column temperature was held at $200^{\circ} \mathrm{C}$ for $10 \mathrm{~min}$, then increased to $230^{\circ} \mathrm{C}$ at $10^{\circ} \mathrm{C} / \mathrm{min}$ and kept at this temperature for $14 \mathrm{~min}$. For routine analysis, peak quantification was performed by comparison with four dilutions of DHA-FAME (Sigma, USA) with C19:0-FAME (Sigma, USA) as internal standard. Retention time of each peak from the sample was compared with a mixed PUFA-standard (Supelco no. 189-19). The results of total fatty acid composition in each lipid class were compared to the results of total fatty acid composition found in cellular lipids extracted by Bligh and Dyer method.

\section{Statistical analysis}

The data was statistically analyzed by using one-way analysis of variance, and significant differences were identified by the Duncan and Tukey's test $(P<0.05)$. The analysis was done by SPSS Version 17.0 software (SPSS, Chicago, IL, USA).

\section{RESULTS AND DISCUSSION}

\section{Effect of culture temperature on growth}

The neighbor-joining $(\mathrm{NJ})$ tree showed the phylogenic position of Aurantiochytrium mangrovei Sk-02 (JF260953) and its related species based on 18S rRNA gene sequences (Fig. 1). The morphology and fatty acid profile of this strain suggested that the genus and specie of this microalga was closely related to Aurantiochytrium mangrovei according to the taxonomy rearrangement of Schizochytrium sp. (26). In this study, A. mangrovei Sk-02 was grown on $40 \mathrm{~g} / \mathrm{L}$ glucose at various 
temperatures. Exponential growth was observed up till an $\mathrm{OD}_{660}$ of ca. 12 and the specific growth rate $(\mu)$ was calculated for all conditions (Fig. 2a). At this point, the cell count reached a plateau (data not shown). The cells accumulated lipid until glucose was exhausted in the culture medium with a linear increase in biomass. At this point, the cells were in the late lipid accumulation phase and the maximum $\mathrm{OD}_{660}$, the maximum biomass $(\mathrm{mg} / \mathrm{L})$ and the maximum total fatty acid content (mg/g-dry cell weight (DCW)) were obtained at $108 \mathrm{~h}$, $93 \mathrm{~h}, 50 \mathrm{~h}, 28 \mathrm{~h}, 23 \mathrm{~h}$ and $32 \mathrm{~h}$ in the cells cultivated at $12^{\circ} \mathrm{C}$, $15^{\circ} \mathrm{C}, 20^{\circ} \mathrm{C}, 25^{\circ} \mathrm{C}, 30^{\circ} \mathrm{C}$ and $35^{\circ} \mathrm{C}$, respectively (Fig. 2a and $2 b)$. The maximum specific growth rate and the consumption rate of glucose in an early growth phase were increased with the growth temperature except for cells grown at $35^{\circ} \mathrm{C}$. The highest $\mu_{\max }$ of $0.15 \mathrm{~h}^{-1}$ and the highest cell number of $2.1 \times 10^{8}$ cells $/ \mathrm{ml}$ were found in the cells grown at $30^{\circ} \mathrm{C}$ (Fig 2c). In contrast to the present study, the growth rates of Aurantiochytrium sp. strain mh0186 were similar even though the temperature was varied from $15-30^{\circ} \mathrm{C}$ and the cultivation was finished at $96 \mathrm{~h}$ for all conditions (23). Thus, the latter results suggested that conditions used for growing mh0186 were oxygen-limited at all temperatures tested.

The biomass significantly increased from $13.2 \pm 0.4$ to $14.7 \pm 0.5 \mathrm{~g} / \mathrm{L}(p<0.05)$. Total fatty acid was analyzed by GC and the GC chromatogram of total fatty acid from cells grown on various growth temperatures was shown in Figure 3. Total fatty acid (TFA) was significantly increased from 300 to 415 $\mathrm{mg} / \mathrm{g}-\mathrm{DCW}$ with an increase in growth temperature from 12 to $30^{\circ} \mathrm{C}$ but TFA decreased to $375 \mathrm{mg} / \mathrm{g}-\mathrm{DCW}$ as the growth temperature was increased to $35^{\circ} \mathrm{C}$ (Table 1). The highest total fatty acid yield of $160 \mathrm{mg} \mathrm{TFA} / \mathrm{g}$ glucose was found in the cells grown at $30^{\circ} \mathrm{C}$ (Table 1). Previously, A. mangrovei Sk-02 was shown to have an optimum temperature for maximal biomass and DHA-formation at ca. $25-30^{\circ} \mathrm{C}(24)$. Another report of the biomass and total fatty acid content of $A$. limacinum OUC88 cultivated in the range of $16-37^{\circ} \mathrm{C}$ were reduced significantly (2.6 and 1.6 times, respectively), as the temperature increased from 30 to $37^{\circ} \mathrm{C}(27)$. The results from previous studies agree with the results found in this study suggesting that $A$. mangrovei could grow well at a wide range of growth temperatures $\left(12\right.$ to $\left.35^{\circ} \mathrm{C}\right)$.

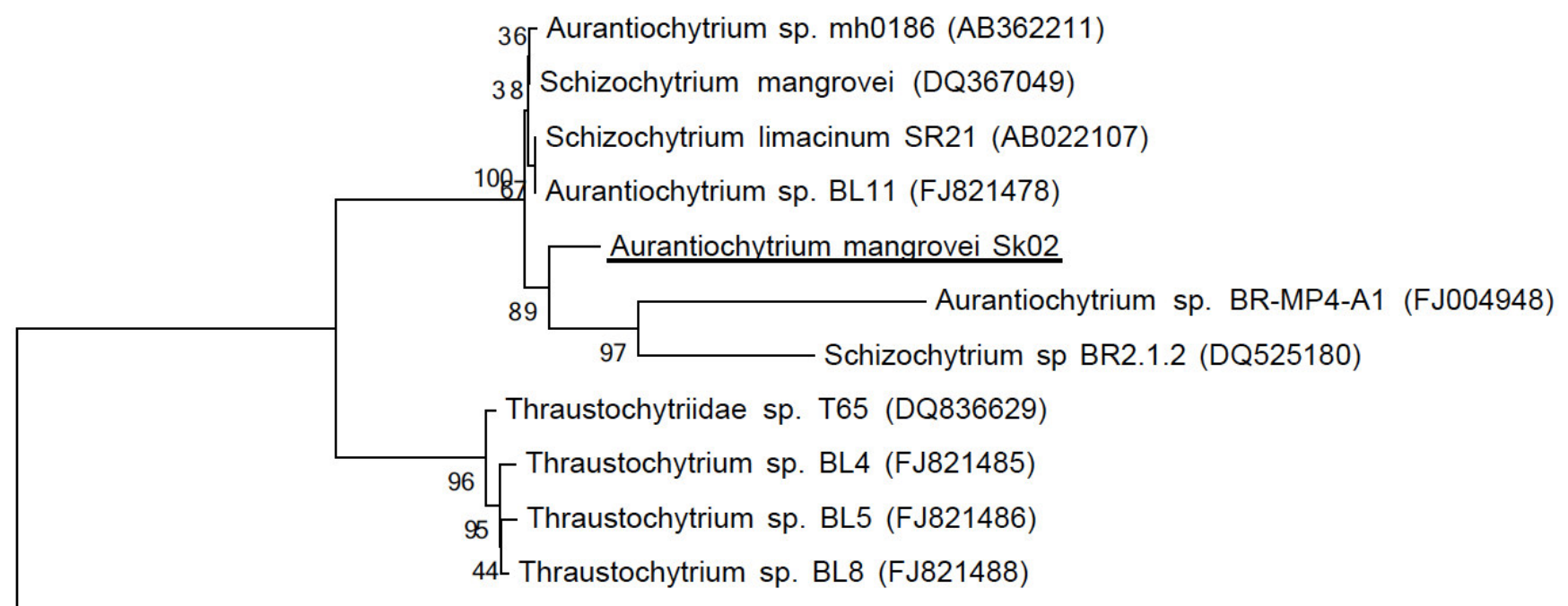

Crypthecodinium cohnii (FJ821501)

0.05

Figure 1. Phylogenic tree of Labyrinthulomyteces using 18S rRNA genes with Cryptheconidium cohnii as out group. 
a)

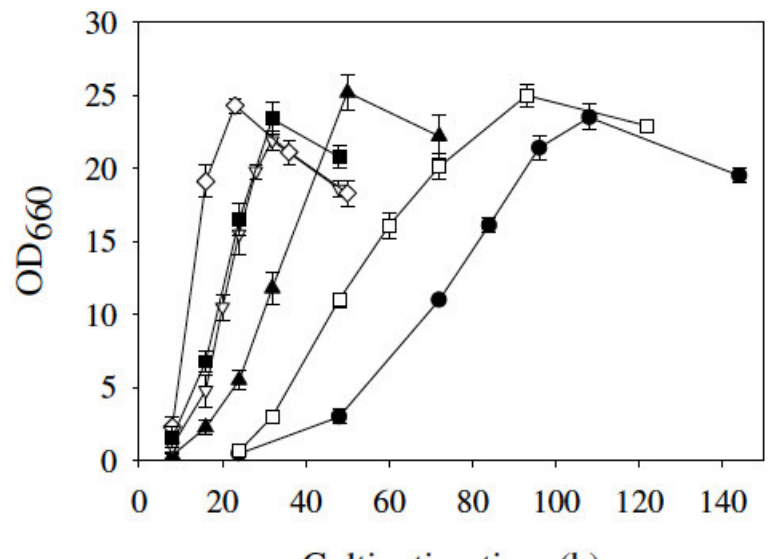

Cultivation time (h)

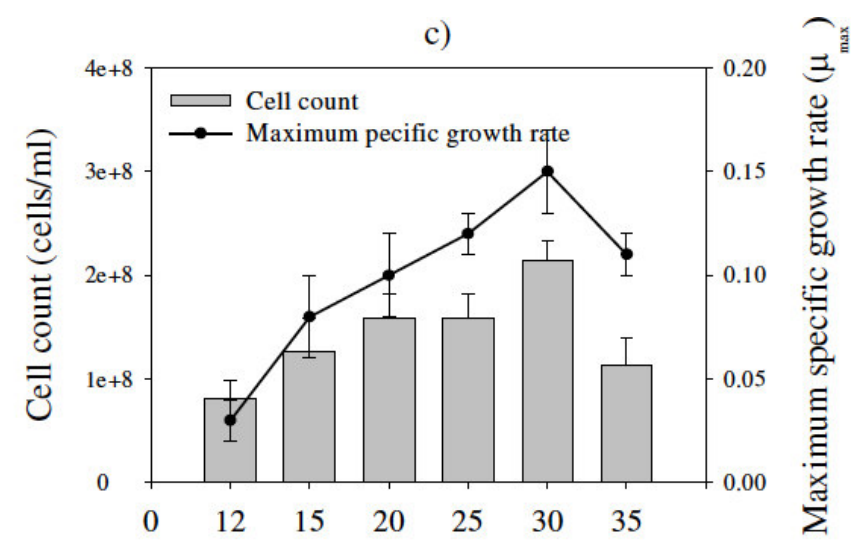

b)

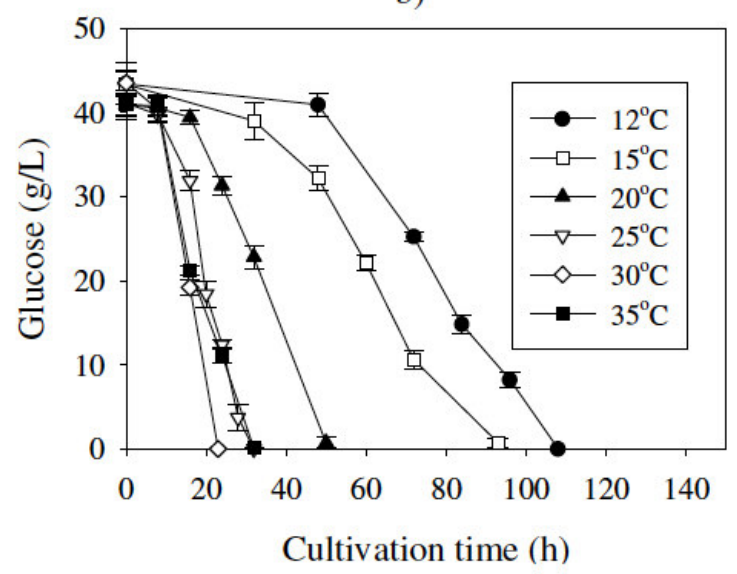

Figure 2. Effect of cultivation temperature on cell growth (a), the residual glucose concentration $(\mathrm{g} / \mathrm{L})(\mathrm{b})$ and the maximum specific growth rate $\left(\mu_{\max }\right)$ (line) and cell count (cells $/ \mathrm{mL}$ ) at the maximum $\mathrm{OD}_{660}$ (bars) (c) of Aurantiochytrium mangrovei Sk-02 as a function of growth temperatures $\left(12^{\circ} \mathrm{C}-35^{\circ} \mathrm{C}\right)$.

Growth temperature (OC)

Table 1. Fatty acid composition (mg/g-dry cell weight $D C W)$ and the total fatty acid yield (mg/g glucose) of A. mangrovei Sk-02 as a function of growth temperature. (The data was obtained from direct acid methylation and the percentages of $\mathrm{C} 16: 1$ and $\mathrm{C} 18: 1$ were less $1 \%$ ).

\begin{tabular}{|c|c|c|c|c|c|c|}
\hline \multirow{2}{*}{$\begin{array}{c}\text { Fatty acid } \\
(\mathrm{mg} / \mathrm{g} \text { DCW })\end{array}$} & \multicolumn{6}{|c|}{ Temperature $\left({ }^{\circ} \mathrm{C}\right)$} \\
\hline & 12 & 15 & 20 & 25 & 30 & 35 \\
\hline $\mathrm{C} 14: 0$ & $8.8 \pm 1.6^{\mathrm{b}}$ & $10.1 \pm 0.9^{b}$ & $8.4 \pm 0.8^{\mathrm{b}}$ & $11.1 \pm 2.3^{b}$ & $14.3 \pm 1.8^{\mathrm{a}}$ & $11.3 \pm 1.5^{\mathrm{b}}$ \\
\hline $\mathrm{C} 15: 0$ & $34.5 \pm 0.3^{\mathrm{b}}$ & $37.9 \pm 1.2^{\mathrm{a}}$ & $33.9 \pm 0.9^{\mathrm{b}}$ & $30.3 \pm 0.4^{\mathrm{c}}$ & $20.4 \pm 0.4^{\mathrm{d}}$ & $22.2 \pm 0.3^{\mathrm{d}}$ \\
\hline C16:0 & $108.9 \pm 9.8^{\mathrm{e}}$ & $145.6 \pm 10.3^{\mathrm{d}}$ & $137.4 \pm 7.5^{\mathrm{d}}$ & $175.6 \pm 9.7^{\mathrm{c}}$ & $228.3 \pm 5.4^{\mathrm{a}}$ & $206.9 \pm 8.5^{b}$ \\
\hline C18:0 & $2.0 \pm 0.4^{\mathrm{c}}$ & $2.2 \pm 0.5^{\mathrm{c}}$ & $2.2 \pm 0.2^{c}$ & $4.0 \pm 0.3^{\mathrm{b}}$ & $4.9 \pm 0.6^{\mathrm{a}}$ & $4.2 \pm 0.2^{\mathrm{ab}}$ \\
\hline $\mathrm{C} 20: 3 \mathrm{n} 6$ & $3.7 \pm 2.1^{\mathrm{a}}$ & $4.3 \pm 0.3^{\mathrm{a}}$ & $2.6 \pm 0.1^{\mathrm{a}}$ & $2.7 \pm 0.8^{\mathrm{a}}$ & $3.2 \pm 2.1^{\mathrm{a}}$ & $3.9 \pm 0.2^{\mathrm{a}}$ \\
\hline $\mathrm{C} 20: 5 \mathrm{n} 3$ & $1.5 \pm 0.3^{\mathrm{a}}$ & $1.1 \pm 0.1^{\mathrm{a}}$ & $0.5 \pm 0.4^{\mathrm{a}}$ & $1.1 \pm 0.7^{\mathrm{a}}$ & $1.1 \pm 0.3^{\mathrm{a}}$ & $0.8 \pm 0.3^{\mathrm{a}}$ \\
\hline $\mathrm{C} 22: 5 \mathrm{n} 6$ & $15.1 \pm 1.5^{\mathrm{d}}$ & $14.0 \pm 0.8^{\mathrm{d}}$ & $13.1 \pm 0.7^{\mathrm{d}}$ & $19.9 \pm 0.1^{\mathrm{c}}$ & $22.9 \pm 0.3^{\mathrm{b}}$ & $27.8 \pm 0.6^{\mathrm{a}}$ \\
\hline $\mathrm{C} 22: 6 \mathrm{n} 3$ & $125.6 \pm 5.2^{\mathrm{a}}$ & $107.8 \pm 8.8^{b}$ & $105.0 \pm 5.6^{\mathrm{b}}$ & $107.4 \pm 2.5^{b}$ & $119.9 \pm 4.6^{\mathrm{a}}$ & $97.7 \pm 7.7^{\mathrm{b}}$ \\
\hline Saturated & $154.2 \pm 11.5^{\mathrm{d}}$ & $195.8 \pm 10.7^{\mathrm{c}}$ & $181.9 \pm 8.4^{\mathrm{c}}$ & $221.0 \pm 9.5^{\mathrm{b}}$ & $268.0 \pm 7.5^{\mathrm{a}}$ & $244.6 \pm 10.6^{b}$ \\
\hline Unsaturated & $146.0 \pm 1.9^{\mathrm{a}}$ & $127.3 \pm 4.3^{b}$ & $120.7 \pm 2.4^{\mathrm{c}}$ & $131.1 \pm 0.7^{\mathrm{b}}$ & $147.0 \pm 2.7^{\mathrm{a}}$ & $130.2 \pm 5.5^{b}$ \\
\hline TFA (mg/g DCW) & $300.2 \pm 10.3^{c}$ & $323.1 \pm 11.3^{d}$ & $302.6 \pm 9.5^{\mathrm{de}}$ & $352.1 \pm 11.3^{c}$ & $415.0 \pm 7.7^{\mathrm{a}}$ & $374.9 \pm 9.7^{b}$ \\
\hline TFA (mg/g glucose) & $99.0 \pm 3.4^{\mathrm{e}}$ & $117.9 \pm 4.1^{\mathrm{cd}}$ & $108.2 \pm 3.4^{\mathrm{de}}$ & $126.7 \pm 4.1^{\mathrm{c}}$ & $159.8 \pm 2.9^{\mathrm{a}}$ & $137.8 \pm 3.8^{\mathrm{b}}$ \\
\hline Biomass (g/L) & $13.2 \pm 0.3^{b}$ & $14.6 \pm 0.5^{\mathrm{ab}}$ & $14.3 \pm 1.1^{\mathrm{ab}}$ & $14.4 \pm 0.9^{\mathrm{ab}}$ & $14.7 \pm 0.3^{\mathrm{a}}$ & $14.7 \pm 0.9^{\mathrm{a}}$ \\
\hline $\mathrm{C} 22: 6 \mathrm{n} 3 / \mathrm{C} 22: 5 \mathrm{n} 6$ & 8.3 & 7.7 & 8.0 & 5.4 & 5.2 & 3.5 \\
\hline $\mathrm{C} 16: 0 / \mathrm{C} 22: 6 \mathrm{n} 3$ & 0.9 & 1.4 & 1.3 & 1.6 & 1.9 & 2.1 \\
\hline
\end{tabular}

* Alphabetic superscripts within the same row but among the different groups indicate statistical

difference $(p<0.05)$ analyzed by One-way ANOVA using the Tukey and Duncan's test. 


\section{Effect of culture temperature on total fatty acid profile}

As shown in Table 1 and Figure 3, the major saturated fatty acid found at all cultivation temperatures was palmitic acid (C16:0) and the major polyunsaturated fatty acid was DHA (C22:6n3). However, the ratio of C16:0 (mg/g-DCW) to C22:6n3 (mg/g-DCW) increased from 0.9 to 2.1 as a growth temperature increased from 15 to $35^{\circ} \mathrm{C}$. In addition, some minor UFAs like C16:1 and C18:1 were also found but they were not included in the data, since the sum of them was less than $1 \%$ of total fatty acid (TFA) or $4 \mathrm{mg} / \mathrm{g}-\mathrm{DCW}$ (data not shown). An increase in growth temperature was accompanied by an increase in the percentages of C16:0, stearic acid (C18:0) and DPA (C22:5n6), except for the condition at $35^{\circ} \mathrm{C}$ (Table 2 ). The percentage of total saturated fatty acid (SFA) increased from 51.4 to $61.3 \%$ of TFA with an increase in growth temperature from 12 to $35^{\circ} \mathrm{C}$. In contrast, the percentage of total unsaturated fatty acid (UFA) was negatively correlated with an increase in the culture temperature (Table 2). The percentage of DHA in total fatty acid (TFA) decreased significantly from 41.8 to $26.1 \%$ whereas, C16:0 increased significantly from $36.3 \%$ to $55.2 \%$ of TFA with an increase in the growth temperature from 12 to $35^{\circ} \mathrm{C}$, respectively (Table 2). These results were in accordance with previous reports. For example, in Aurantiochytrium sp. strain mh0186, the amount of UFA and DHA decreased 1.2-times and at 1.3times, when the temperature increased from 10 to $15^{\circ} \mathrm{C}$, respectively (23). Similarly, in A. limacinum, the amount of DHA decreased from 37.6 to $24.8 \%$ of TFA but C16:0 increased from 38.0 to $41.6 \%$ of TFA when the cultivation temperature increased from 16 to $30^{\circ} \mathrm{C}(27)$.

In order to study, whether growth was oxygen limited, experiments were conducted in which the initial liquid volume was varied in $500 \mathrm{~mL}$ baffled flasks containing 50 to $250 \mathrm{~mL}$ in $50 \mathrm{~mL}$ increments at $30^{\circ} \mathrm{C}$. Only at a volume of larger than $150 \mathrm{~mL}$, a decrease in $\mu_{\max }$ or linear growth was observed (data not shown). Hence, oxygen was not limited in the conditions used in this study. Alternatively or additionally, the FA profile might be a function of the specific growth rate $(\mu)$, which was strongly dependent on the cultivation temperature (Fig 2c). Hence it can be argued that experiments should be performed in a chemostat (continuous culture, chemostat) at a fixed dilution $=$ growth rate. However, experiments with various oleaginous microbes suggest that in chemostat the biomass and/or lipid content decreases rapidly with increasing growth rates in N-limited media as shown for instance with an oleaginous mould Entomophthora exitalis (13) as well as Schizochytrium sp. GS13/2S (7). In the context of Fig 2c, this would imply that dilution rate would have to be set as low as $0.01 \mathrm{~h}^{-1}$ to avoid wash-out at low cultivation temperatures. It would be difficult and very time-consuming to get a steady state under such conditions, hence this was not pursued. Furthermore, trends in TFA profiles versus cultivation temperature reported for Aurantiochytrium sp. mh0186 where similar to those reported in the present study (23). However, for mh0186, growth curves were linear and similar for all temperatures tested, suggesting that specific growth rate might not be the major factor determining FA-profiles, although this cannot be ruled out.

Unfortunately, the actual intermediates of PUFA production by PKS pathway have not been identified so far. However, the enzyme reactions in PKS pathway showed that DPA was not an intermediate for DHA synthesis in the PKS pathway (16), hence a separate pathway can be postulated. In our study a clear effect of temperature on the ratio of DHA (C22:6n3) to DPA (C22:5n6) was observed, for example, the ratio was 8.3 at $12^{\circ} \mathrm{C}$ and 3.5 at $35^{\circ} \mathrm{C}$ (Table 1). These results were in agreement with the trend reported for A. limacinum SR21 and Aurantiochytrium sp. strain mh0186, respectively (27, 23). Hence, the regulation of the DPA versus DHA formation appeared to be quite different and it can be concluded that DPA was not a precursor for DHA as already suggested (20). The odd-number fatty acid (pentadecanoic acid, C15:0) was synthesized from propionyl CoA derived from specific amino acids present in yeast extract. Propionyl 
CoA was then condensed with malonyl $\mathrm{CoA}$ by $\mathrm{KS}$, the first enzyme in the FAS pathway. In this study, C15:0 decreased from 37.9 to $20.4 \%$ with an increase in the cultivation temperature from 15 to $30^{\circ} \mathrm{C}$ (Table 2). So, the production of
C15:0 might be dependent on the nitrogen metabolism which was controlled by the growth rate during nitrogen assimilation as well as the growth temperature. a)

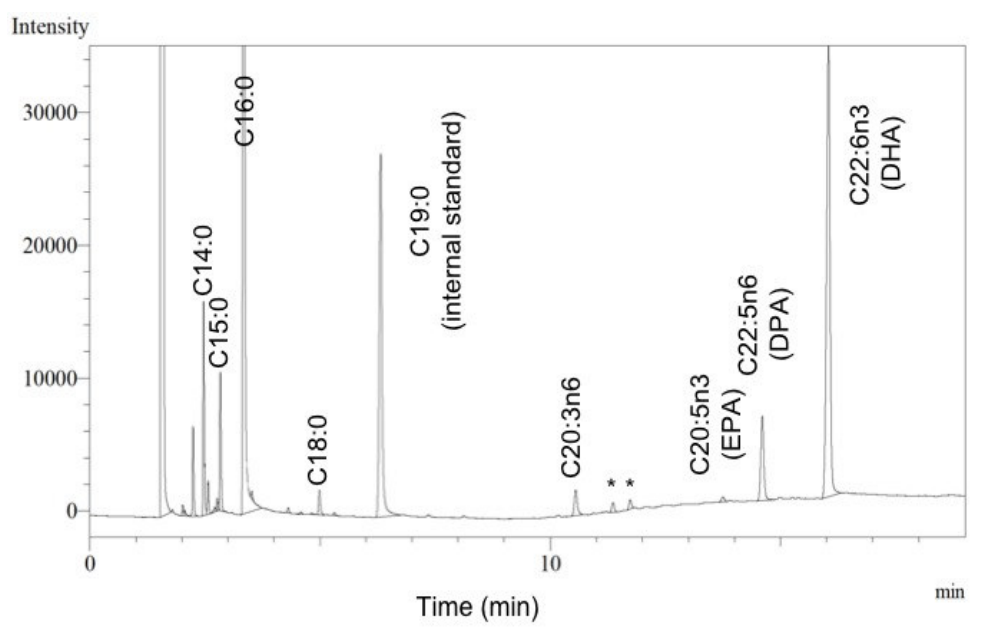

b)

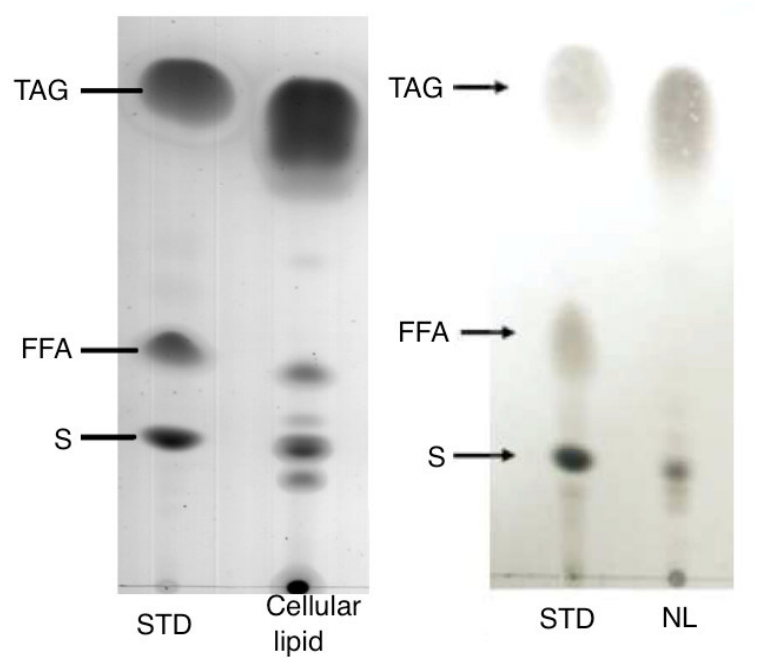

Figure 3. GC chromatogram of methyl-esterified fatty acids from glucose grown cells and from lipid class separation (NL, FFA and PL) at various growth temperatures (Star indicates unidentified peak) (a) and TLC of neutral lipid (NL) class (major lipid class) separated from cellular lipids compared to standard triacylglycerol (TAG), free fatty acid (FFA) and sterol (S) (b).

Table 2. Fatty acid composition (\% total fatty acid) of $A$. mangrovei Sk-02 as a function of growth temperature. (The data was obtained from direct acid methylation and the percentages of $\mathrm{C} 16: 1$ and $\mathrm{C} 18: 1$ were less 1\%).

\begin{tabular}{ccccccc}
\hline Fatty acid & \multicolumn{7}{c}{ Temperature $\left({ }^{\circ} \mathbf{C}\right)$} \\
\cline { 2 - 7 }$(\boldsymbol{\%})$ & $\mathbf{1 2}$ & $\mathbf{1 5}$ & $\mathbf{2 0}$ & $\mathbf{2 5}$ & $\mathbf{3 0}$ & $\mathbf{3 5}$ \\
\hline $\mathrm{C} 14: 0$ & $2.9 \pm 0.3^{\mathrm{a}}$ & $3.1 \pm 0.2^{\mathrm{a}}$ & $2.8 \pm 0.3^{\mathrm{a}}$ & $3.1 \pm 0.6^{\mathrm{a}}$ & $3.5 \pm 0.2^{\mathrm{a}}$ & $3.0 \pm 0.2^{\mathrm{a}}$ \\
$\mathrm{C} 15: 0$ & $11.5 \pm 0.2^{\mathrm{a}}$ & $11.7 \pm 0.1^{\mathrm{a}}$ & $11.2 \pm 0.1^{\mathrm{b}}$ & $8.6 \pm 0.2^{\mathrm{c}}$ & $4.9 \pm 0.1^{\mathrm{e}}$ & $5.9 \pm 0.1^{\mathrm{d}}$ \\
$\mathrm{C} 16: 0$ & $36.3 \pm 0.9^{\mathrm{d}}$ & $45.1 \pm 0.4^{\mathrm{c}}$ & $45.4 \pm 0.3^{\mathrm{c}}$ & $49.9 \pm 0.3^{\mathrm{b}}$ & $55.0 \pm 0.8^{\mathrm{a}}$ & $55.2 \pm 0.2^{\mathrm{a}}$ \\
$\mathrm{C} 18: 0$ & $0.7 \pm 0.1^{\mathrm{b}}$ & $0.7 \pm 0.0^{\mathrm{b}}$ & $0.7 \pm 0.1^{\mathrm{b}}$ & $1.1 \pm 0.2^{\mathrm{a}}$ & $1.2 \pm 0.1^{\mathrm{a}}$ & $1.1 \pm 0.1^{\mathrm{a}}$ \\
$\mathrm{C} 20: 3 \mathrm{n} 6$ & $1.2 \pm 0.5^{\mathrm{a}}$ & $1.3 \pm 0.5^{\mathrm{a}}$ & $0.9 \pm 0.1^{\mathrm{a}}$ & $0.8 \pm 0.4^{\mathrm{a}}$ & $0.8 \pm 0.4^{\mathrm{a}}$ & $1.0 \pm 0.1^{\mathrm{a}}$ \\
$\mathrm{C} 20: 5 \mathrm{n} 3$ & $0.5 \pm 0.1^{\mathrm{a}}$ & $0.3 \pm 0.0^{\mathrm{a}}$ & $0 \pm 0.0^{\mathrm{a}}$ & $0.3 \pm 0.3^{\mathrm{a}}$ & $0.2 \pm 0.1^{\mathrm{a}}$ & $0.2 \pm 0.2^{\mathrm{a}}$ \\
$\mathrm{C} 22: 5 \mathrm{n} 6$ & $5.0 \pm 0.2^{\mathrm{c}}$ & $4.3 \pm 0.1^{\mathrm{d}}$ & $4.3 \pm 0.4^{\mathrm{d}}$ & $5.7 \pm 0.1^{\mathrm{b}}$ & $5.5 \pm 0.2^{\mathrm{b}}$ & $7.4 \pm 0.3^{\mathrm{a}}$ \\
C22:6n3 & $41.8 \pm 1.8^{\mathrm{a}}$ & $33.4 \pm 0.2^{\mathrm{b}}$ & $34.7 \pm 0.1^{\mathrm{b}}$ & $30.5 \pm 0.1^{\mathrm{c}}$ & $28.9 \pm 1.8^{\mathrm{c}}$ & $26.1 \pm 0.1^{\mathrm{d}}$ \\
Saturated & $51.4 \pm 1.1^{\mathrm{d}}$ & $60.6 \pm 0.3^{\mathrm{c}}$ & $60.1 \pm 0.2^{\mathrm{c}}$ & $62.8 \pm 0.3^{\mathrm{b}}$ & $64.6 \pm 1.2^{\mathrm{a}}$ & $65.3 \pm 0.1^{\mathrm{a}}$ \\
Unsaturated & $48.6 \pm 0.9^{\mathrm{a}}$ & $39.4 \pm 0.2^{\mathrm{b}}$ & $39.9 \pm 0.2^{\mathrm{b}}$ & $37.2 \pm 0.3^{\mathrm{c}}$ & $35.4 \pm 0.8^{\mathrm{d}}$ & $34.7 \pm 0.2^{\mathrm{d}}$ \\
UI & 2.8 & 2.3 & 2.3 & 2.2 & 2.0 & 2.0 \\
\hline * Unsaturation index $($ UI) $=(1.0(\%$ monoene $))+(2.0(\%$ diene $))+(3.0(\%$ triene $))+(4.0(\%$ tetraene $))+(5.0(\%$ pentaene $)$ \\
+ (6.0(\%hexaene $)) / 100$ \\
Alphabetic superscripts within the same row but among the different groups indicate statistical
\end{tabular}




\section{Fatty acid composition of major lipid classes}

The major lipid classes of $A$. mangrovei Sk-02 grown at various temperatures in the late lipid accumulation phase were separated. The results of fatty acid composition in lipid extracted from the cells by Bligh and Dyer method before lipid class separation were compared to the result of fatty acid composition in each lipid class after lipid classes were separated by column chromatography. The results of the sum of fatty acid composition in all classes after lipid class separation were similar to the result found in total lipid extracted before lipid class separation. Moreover, the results of GC analysis of cells by direct methylation method were similar to the results of fatty acid composition of lipid extracted from the Bligh and Dyer method followed by acid methylation for GC analysis (Fig. 3a). The data from this study showed that cells stored lipid predominantly in the form of neutral lipid (NL) (> 75\% of total cellular lipid). NL was composed of triacylglycerol (TAG), diacylglycerol (DAG), monoacylglycerol (MAG), sterol ester (SE) and sterol (S) as shown by TLC of NL from cells grown at various temperatures (Fig .3b). In addition, FFA and PL were also visible on TLC (Fig. 3b). In order to exclude the possibility that FFA arose from lipase activity during handling, fresh cells were heated at $70^{\circ} \mathrm{C}$ for 15 min which abolished intracellular lipase as assayed in cell-free extracts by pNPP measurement (data not shown) but gave identical TLC patterns as non-heated cells. FFA accounted for $3-5 \%$ of the total cellular lipid weight and total PL was approximately $18 \%$ of total cellular lipid. The data was independent of the cultivation temperature (Fig. 4).

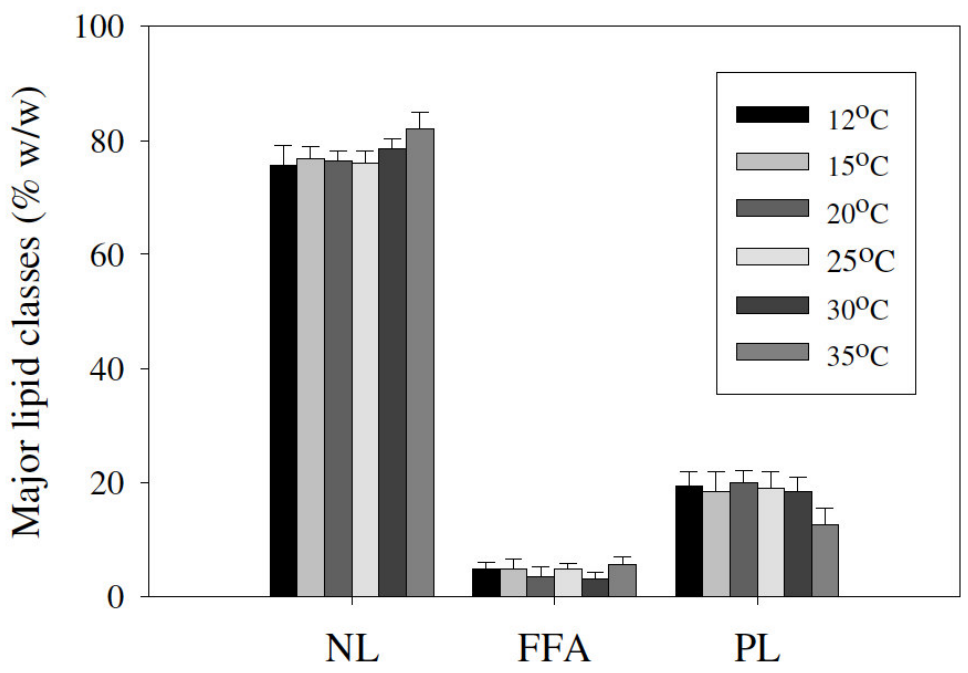

Figure 4. The weight percentage (+/- S.D.) of individual major lipid classes from A. mangrovei Sk-02 as a function of growth temperature (12 $\left.35^{\circ} \mathrm{C}\right) . \mathrm{NL}=$ neutral lipid, FFA $=$ free fatty acid and $\mathrm{PL}=$ phospholipid.
Figure 5 shows the influence of growth temperature on the fatty acid composition in NL. Similar to the results of fatty acid composition from overall cellular fatty acid profile, C16:0 slightly increased with an increase in the growth temperature from 12 to $25^{\circ} \mathrm{C}$ and remained constant from 30 to $35^{\circ} \mathrm{C}$. In contrast, $\mathrm{C} 15: 0$ and DHA decreased from 13.6 to $6.7 \%$ of TFA and 40.7 to $24.9 \%$ of TFA in NL, respectively when the growth temperature increased from 12 to $35^{\circ} \mathrm{C}$ (Fig. 5). In phospholipids, the percentage of DHA decreased significantly from 53.5 to $35.5 \%$ of TFA in total PL whereas C16:0 increased markedly from $39.9 \%$ to $52.0 \%$ of TFA in PL as the growth temperature increased from 12 to $35^{\circ} \mathrm{C}$ (Fig. 6). The major fatty acid composition in NL and PL as a function of temperature were basically similar but the percentage of DHA in total fatty acid of total PL was higher as compared to that in NL (Fig. 5 and Fig. 6). For C20 PUFAs (C20:3n6 and 
C20:5n3), a similar decrease with increasing growth temperature would be expected but due to the low absolute levels of these two PUFAs a significant trend could not be established (Fig. 5 and Fig. 6). Phospholipids from cells grown at $15^{\circ} \mathrm{C}$ and $30^{\circ} \mathrm{C}$ were chosen as examples of cells grown at low and high growth temperature for the separation of non-acidic phospholipid (non-aPL) and acidic phospholipid (aPL). Previous research has shown that the predominant PL in A. mangrovei consisted of PC and PE (5). In Sk-02, 60 - 70\% of total PL consisted of non-acidic PL under all growth conditions (data not shown). In phospholipids, DHA in
non-aPL was much higher than in aPL in which C16:0 was the main fatty acid. DHA (\%) in non-aPL also decreased from 68.5 to $48.5 \%$ of TFA with an increase in the growth temperature from 15 to $30^{\circ} \mathrm{C}$ (Fig. 7). These results were in agreement with the results found in A. mangrovei $\mathrm{FB} 3$ grown at $25^{\circ} \mathrm{C}$ as non-aPL in this microalgae made up of ca. $60 \%$ of PL (5). Moreover, the percentage of DHA in total PC (a non-aPL) of the thraustochytridlike strain 12B was approximately $54 \%$, while only $20 \%$ of total PL was found in PI (an acidic phospholipid) in cells cultivated at $30^{\circ} \mathrm{C}(18)$.

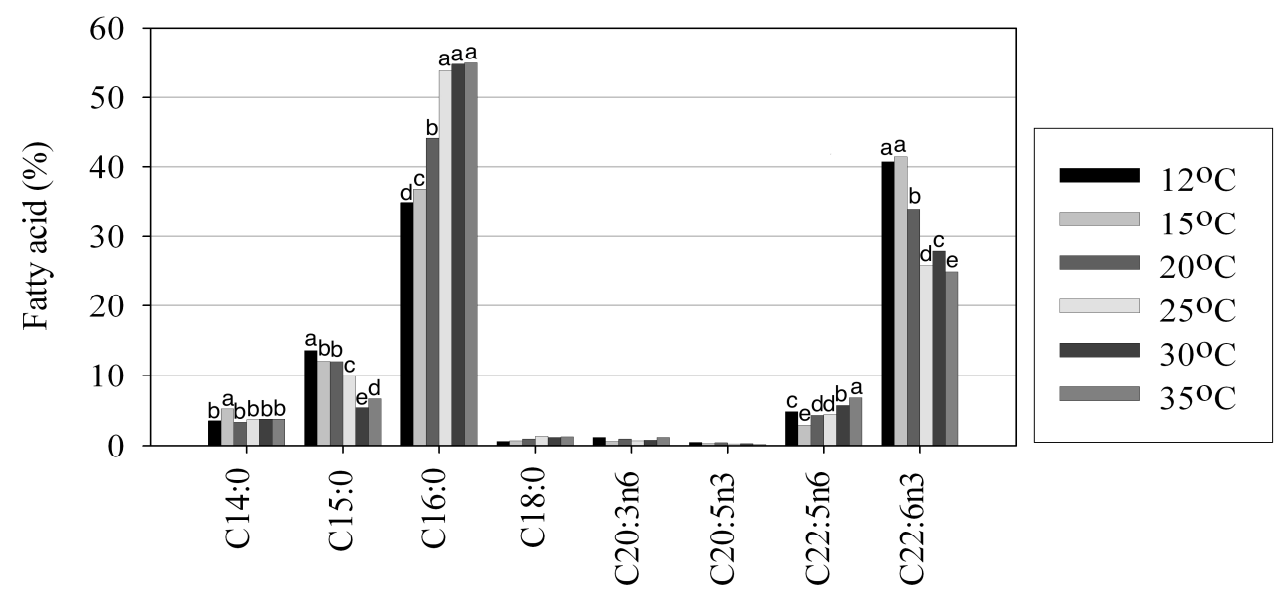

Figure 5. Fatty acid composition in neutral lipid of cells grown at different growth temperature (S.D.< 1.0). Alphabets above each bar graph indicate a significant difference $(p<0.05)$.

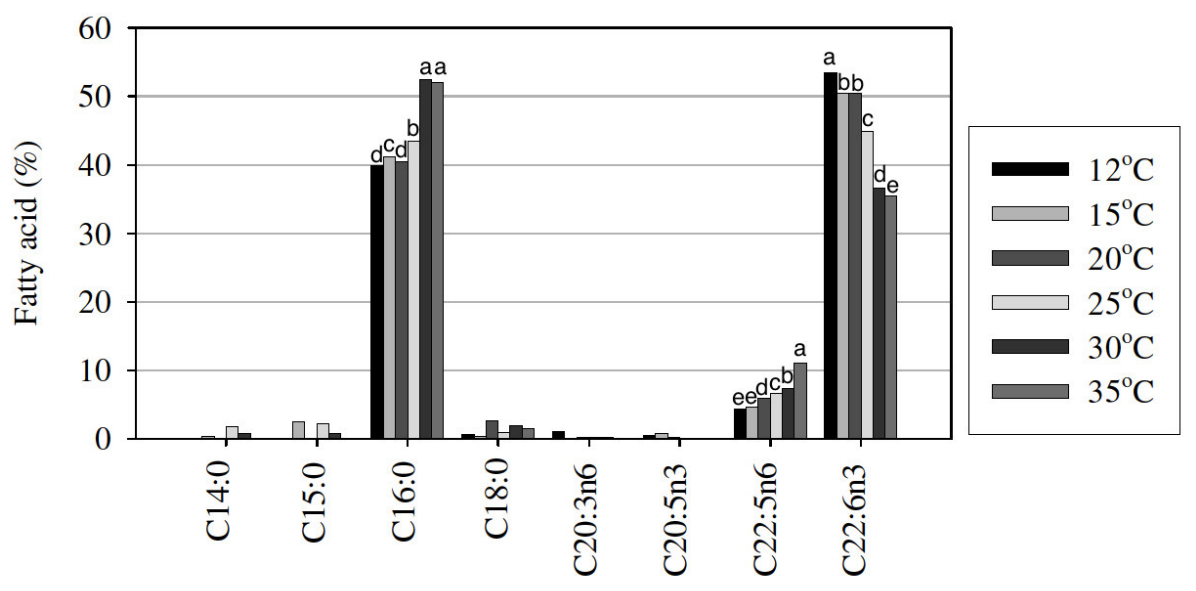

Figure 6. Fatty acid composition in total phospholipids of cells grown at different temperatures (S.D. <1.0). Alphabets above each bar graph in a group of $\mathrm{C} 16: 0, \mathrm{C} 22: 5 \mathrm{n} 6$ and $\mathrm{C} 22: 6 \mathrm{n} 3$ indicate a significant difference $(p<0.05)$. 


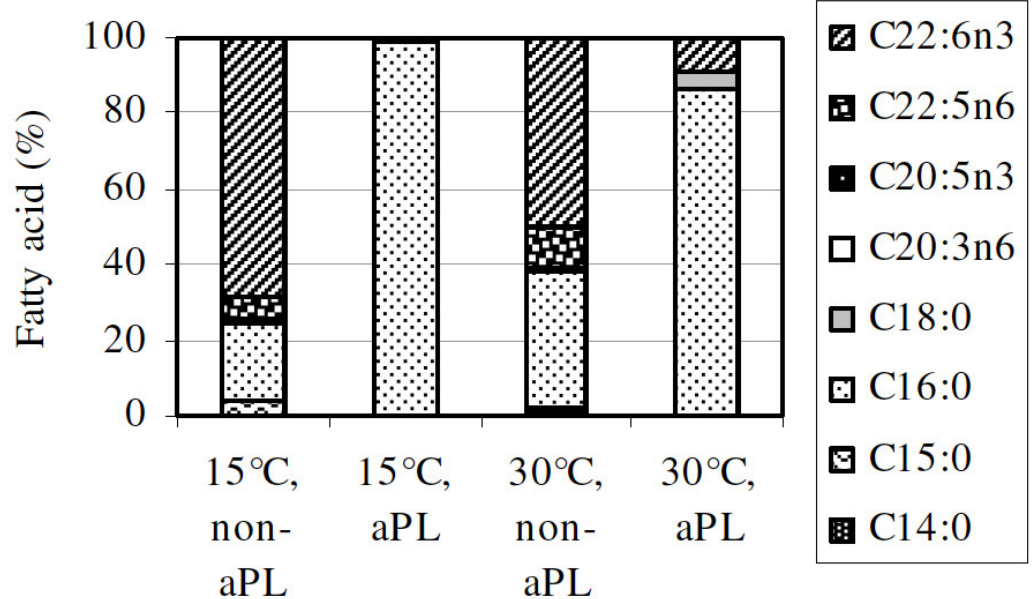

Figure 7. Fatty acid composition of non-acidic phospholipid (non-aPL) and acidic phospholipid (aPL) of cells grown at $15^{\circ} \mathrm{C}$ and $30^{\circ} \mathrm{C}$.

\section{Lipid fluidity measurement}

Fresh cells cultivated at $15^{\circ} \mathrm{C}$ and $30^{\circ} \mathrm{C}$ until the late lipid accumulation stage were chosen as examples of cells grown at low and high growth temperature, respectively. In order to study the lipid fluidity of the cells grown at two different temperatures, the temperatures for fluidity measurement were set at $15^{\circ} \mathrm{C}, 30^{\circ} \mathrm{C}$ and $37^{\circ} \mathrm{C}$. The common used probes -DPH and TMA-DPH- had different in the polarities. DPH had no head group whereas TMA-DPH was a cationic derivative of DPH molecule, which can anchor at the surface region of the plasma membrane (4). As the temperature for measurements increased, the lipid fluidity measured with DPH from both conditions increased significantly $(p<0.05)$ (Fig. 8). For TMA$\mathrm{DPH}$, the anisotropy value was only slightly affected by the temperature of measurement. Cells cultivated at $30^{\circ} \mathrm{C}$ had less fluidity as compared to cells cultivated at $15^{\circ} \mathrm{C}$ when measured at $15^{\circ} \mathrm{C}$ by TMA-DPH probe. Thus, this study showed that $A$. mangrovei Sk-02 can maintain a constant plasma membrane fluidity at a wide range of the environmental temperatures. In contrast, lipid fluidity in the intracellular lipid as well as the intracellular membrane was highly affected by the growth temperature as indicated by significant changes in anisotropy value of DPH as a function of growth temperature. These results were in agreement with a study on the effect of temperature on crab plasma membrane fluidity measured by DPH and TMA-DPH as the temperature of measurement increased from 5 to $35^{\circ} \mathrm{C}(4)$.

Highly unsaturated fatty acids such as DHA and DPA can induce a change in the lipid bilayer structure as their kinked molecules might loosen the packed structure of the membrane lipid bilayer However, the properties and functions of DHA in terms of increasing membrane fluidity in Thraustochytrids still remain unclear (11) as a very high fluidity of membrane itself might not be necessary for microorganisms living in such shallow waters and moderate water pressure as present in mangrove forests where Aurantiochytrium sp. are commonly isolated. In addition, not only DHA and DPA as found in Aurantiochytrium $s p$. but also monounsaturated fatty acids like C18:1 could also increase the fluidity of the plasma membrane. This was clearly shown in the deep sea bacterium Photobacterium profundum SS9 from which the PKS gene cluster for EPA-production was deleted and oleic acid (C18:1n9) added to the medium. This allowed good growth at either low temperature or high pressure, suggesting that highly unsaturated fatty acids were not essential for the cells to survive in extreme conditions (1). Hence, the function of DHA/DPA in thraustochytrids remains unclear. 


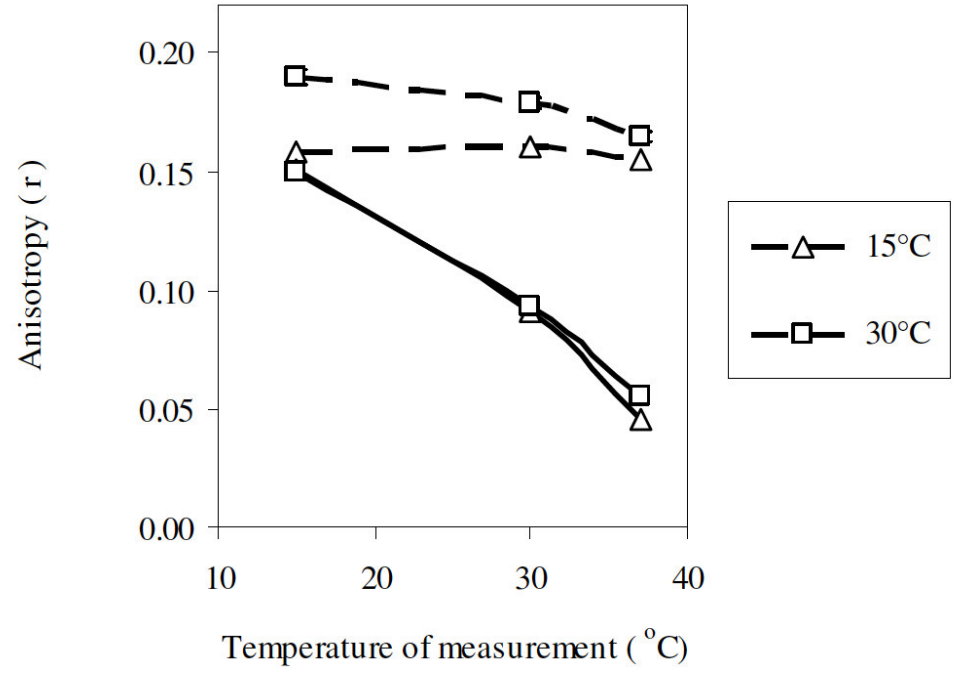

Figure 8. The temperature dependence of fluorescence anisotropy measured by DPH (solid lines) and TMA-DPH (broken lines) of cells cultivated at $15^{\circ} \mathrm{C}$ and $30^{\circ} \mathrm{C}$ (S.D. < $0.01)$.
Implications for commercial production of DHA from Aurantiochytrium mangrovei

From this study, the growth temperature for the industrial scale production of DHA by A. mangrovei was in the range of 25 to $30^{\circ} \mathrm{C}$. However, the temperature for producing DHArich cells (ca. $34.2 \%$ to $43.8 \%$ of TFA) could be in the range of 12 to $20^{\circ} \mathrm{C}$. But the cost for cooling the reactor down to a very low temperature was high and the time to finish the cultivation was longer as compared to that at high temperature (25 to $35^{\circ} \mathrm{C}$ ). Therefore, it might be not worth for the large scale production to cultivate the microorganism at low temperature and effort should rather be focused on screening for a strain with a high DHA/DPA content. For example, DHA of strain G13/2S was $43 \%$ of TFA in batch fermentation at $27^{\circ} \mathrm{C}(7)$. The forms of lipid containing in A. mangrovei were mainly NL, FFA and PL. The percentage of DHA $(68.5 \%$ or $65 \mathrm{~mol} \%$ of TFA) in non-aPL at $15^{\circ} \mathrm{C}$ (Fig. 7) showed that it might be possible to have PC with DHA at both $s n-1$ and $s n-2$ position as one molecule of phospholipid is composed of 2 moles of free fatty acids. Therefore, PL in particularly DHA-containing non-aPL, especially PC in both the residual oil after TAG purification and the cell debris could be an interesting byproduct to add more value to large scale production of DHA from Aurantiochytrium sp. It has been suggested that DHAcontaining phospholipids are a better form of DHA as they are two times more bioavailable in the brain than in triacylglycerol or ethyl esters forms (14). Moreover, a report on the development of fish larvae by feeding DHA in the form of TAG and PL showed that DHA-containing PL was more effective than TAG-containing DHA (8).

\section{CONCLUSIONS}

This study was carried out to show the growth, total fatty acid profile, the distribution of DHA in major lipid classes and lipid fluidity of the plasma membrane of A. mangrovei Sk-02 as a function of growth temperature. Cells could grow well over wide range of temperature $\left(12\right.$ to $\left.35^{\circ} \mathrm{C}\right)$. Moreover, the production of PUFA/TFA was inversely related to the growth temperature with similar trends were also found in NL and PL classes. In addition, cells could maintain their plasma membrane fluidity in a wide range of growth temperature, and only the intracellular lipid and organelle membrane were affected by the growth temperature. Furthermore, the results in terms of growth and lipid characterization as a function of temperature could imply for the commercial production of 
DHA from A. mangrovei. Thus, A. mangrovei could be one of the potential candidates for DHA production in the form of dried cells and extracted oil for animal feed and human consumption in both triacylglycerol form and especially, phospholipid form as PC (non-aPL).

\section{ACKNOWLEDGEMENTS}

This research work was partially supported by a RA scholarship from the Faculty of Graduate Studies, Mahidol University. The authors are grateful to Asst. Prof. Noppawan Phumala Morales for her kind support with anisotropy measurements and Dr. Thipa Asvarak for her kind support with 18S rRNA technique.

\section{REFERENCES}

1. Allen, E.E.; Facciotti, D.; Bartlett, D.H. (1999) Monounsaturated but not polyunsaturated fatty acids are required for growth of the deep-sea bacterium Photobacterium profundum SS9 at high pressure and low temperature. Appl Environ Microbiol 65:1710 - 1720.

2. Bligh, E.G.; Dyer, W.J. (1959) A rapid method of total lipid extraction and purification. Can J Biochem Physiol 37:911-917.

3. Cannon, D. (2009) From fish oil to microalgae oil : A win-win shift for humans and our habitat. Explore 5:299-303.

4. Cuculescu, M.; Hyde, D.; Bowler, K. (1995) Temperature acclimation of marine crabs : changes in plasma membrane fluidity and lipid composition. J Therm Biol 20:207 - 222.

5. Fan, K.W.; Jiang, Y.; Faan, Y.W.; Chen, F. (2007). Lipid characterization of mangrove Thraustochytrid -Schizochytrium mangrovei. J Agric Food Chem 55: 2906-2910.

6. Folmer, V.; Pedroso, N.; Matias, A.C.; Lopez, S.C.D.N. et al (2008) $\mathrm{H}_{2} \mathrm{O}_{2}$ induces rapid biophysical and permeability changes in the plasma membrane of Sacchromyces cerevisiae. BBA-Biomembranes 1778:1141 -1147 .

7. Ganuza, E.; Izquierdo, M.S. (2007) Lipid accumulation in Schizochytrium G13/2S produced in continuous culture. Appl Microbiol Biotechnol 76:985 - 990.

8. Gisbert, E.; Villeneuve, L.; Zambonino-Infante, J.; Quazuguel, P. et al (2005) Dietary phospholipids are more efficient than neutral lipids for long-chain polyunsaturated fatty acid supply in European sea bass Dicentrarchus labrax larval development. Lipids 40:609-618.
9. Giusto, N.M.; Pasquare, S.J.; Salvador, P.I.; Roque, M.G. (2000) Lipid metabolism in vertebrate retinal rod outer segments. Prog Lipid Res $39: 315-391$

10. Jacobsen, A.N.; Aasen, I.M.; Josefsen, K.D.; Strom, A.R. (2008) Accumulation of docosahexaenoic acid-rich lipid in thraustochytrid Aurantiochytrium sp. strain T66 : effects of $\mathrm{N}$ and $\mathrm{P}$ starvation and $\mathrm{O}_{2}$ limitation. Appl Microbiol Biotechnol 80:297 - 306.

11. Jain, R.; Raghukumar, S.; Sambaiah, K.; Kumon, Y. et al (2007) Docosahexaenoic acid accumulation in thraustochytrids: search for the rationale. Mar Biol 151:1657-1664.

12. Kaluzny, M.A.; Duncan, L.A.; Merritt, M.V.; Eppse, D.E. (1985) Rapid separation of lipid classes in high yield and purity using bonded phase columns. J Lipid Res 26:135 - 140.

13. Kendrick, A.; Ratledge, C. (1992) Lipid formation in the oleaginous mould Entomophthora exitalis grown in continuous culture: effects of growth rate, temperature and dissolved oxygen tension on polyunsaturated fatty acids. Appl Microbiol Biotechnol 37:18-22.

14. Kidd, P.M. (2007) Omega-3 DHA and EPA for cognition behavior and mood : clinical findings and structural functional synergies with cell membrane phospholipids. Altern Med Rev 12:207 - 227.

15. Lewis, T.E.; Nichols, P.D.; McMeekin, T.A. (2000) Evaluation of extraction methods for recovery of fatty acids from lipid producing microheterotrophs. J Microbiol Methods 43:107 - 116.

16. Metz, J.G.; Roessler, P.; Facciotti, D.; Levering C. et al (2001) Production of polyunsaturated fatty acids by Polyketide synthases in both prokaryotes and eukaryotes. Science 293: 290-293.

17. Moore, S.A.; Hurt, E.; Yoder, E.; Sprecher, H. (1995) Docosahexaenoic synthesis in human skin fibroblasts involves peroxisomal retroconversion of tetracosahexaenoic acid. J Lipid Res 36:2433-2443.

18. Okuyama, H.; Orikasa, Y.; Nishida, T. (2007) In vivo conversion of triacylglycerol to docosahexaenoic acid-containing phospholipids in a thraustochytrid-like microorganism, strain 12B. Biotechnol Lett 29:1977 -1981 .

19. Qui, X. (2003) Biosynthesis of docosahexaenoic acid (DHA, 22:6-4, 7, 10, 13, 16, 19): two distinct pathways. Prostaglandins Leukot Essent Fatty Acids 68:181-186.

20. Ratledge, C. (2004) Fatty acid biosynthesis in microorganisms being used for single cell oil production. Biochemie 86:807-815.

21. Sijtsma, L.; Swaaf, M.E. (2004) Biotechnological production and applications of the omega-3 polyunsaturated fatty acid docosahexaenoic acid. Appl Microbiol Biotechnol 64:146-153.

22. Tamura, K.; Dudley, J.; Nei, M.; Kumar, S. (2007) MEGA4: molecular evolutionary genetics analysis (MEGA) software version 4.0. Mol Biol Evol 24:1596 - 1599.

23. Taoka, Y.; Nagano, N.; Okita, Y.; Izumida, H. et al (2009) Influences of culture temperature on the growth, lipid content and fatty acid 
composition of Aurantiochytrium sp. Strain mh0186. Mar Biotechnol $11: 368-374$

24. Unagul, P.; Assantachai, C.; Phadungruengluij, S.; Suphantharika, M. et al (2005) Properties of the docosahexaenoic acid-producer Schzochytrium mangrovei Sk-02 : effect of glucose, temperature and salinity and their interaction. Botanica Marina 48:387 - 394.

25. Yang, H.L.; Lu, C.K.; Chen, S.F.; Chen, Y.M. et al (2010) Isolation and characterization of Taiwanese heterotrophic microalgae : screening of strains for docosahexaenoic acid (DHA) production. Mar Biotechnol 12: $173-185$.
26. Yokoyama, R.; Honda, D. (2007) Taxonomic rearrangement of the genus Schizochytrium sensu lato based on morphology, chemotaxonomical characteristics and 18S rRNA gene phylogeny (Thraustochytriaceae, Labyrinthulomycetes, stramenopiles): emendation for Schizochytrium and erection of Aurantiochytrium and Oblongichytrium gen. nov. Mycoscience 48: 199-211.

27. Zhu, L.; Zhang, X.; Ji, L.; Song, X. et al (2007) Changes of lipid content and fatty acid composition of Schizochytrium limacinum in response to different temperatures and salinities. Process Biochem 42:210-214. 